\title{
Influence of latent 'asymptomatic' toxoplasmosis on body weight of pregnant women
}

\author{
Jaroslav Flegr ${ }^{1}$, Štěpánka Hrdá ${ }^{1}$ and Petr Kodym ${ }^{2}$ \\ ${ }^{1}$ Department of Parasitology, Charles University, Viničná 7, 12844 Prague, Czech Republic; \\ ${ }^{2}$ National Reference Laboratory for Toxoplasmosis, National Institute of Public Health, Šrobárova 48, 10042 Prague, Czech \\ Republic
}

Key words: parasite, Toxoplasma, latent toxoplasmosis, pathology, permutation test, gravidity

\begin{abstract}
The latent toxoplasmosis is usually considered to be asymptomatic, however, this paradigm has never been rigorously tested. Here we searched for symptoms of deterioration of physical health (decrease of weight) in infected people by analysis of clinical records of 758 women tested for toxoplasmosis in the 16th week of gravidity. Toxoplasma-positive women have a lower body weight in the 16th week of gravidity $(\mathrm{p}=0.02)$ than Toxoplasma-negative women. Moreover, a negative correlation between weight and the duration of toxoplasmosis was found in a subset of 174 Toxoplasma-positive women $(p=0.04)$, suggesting that slow and cumulative effects of latent toxoplasmosis, rather than a transient effect of acute toxoplasmosis, are responsible for the decreased weight of infected subjects. Longer duration of gravidity estimated from the date of last menstruation in the set of Toxoplasma-positive women in the 16th week of gravidity estimated with ultrasonography $(\mathrm{p}=0.04)$ suggests a possibility of retarded foetal growth in Toxoplasma-positive women. The prevalence of latent toxoplasmosis is extremely high. Therefore, even its mild symptoms such as the decreased body weight in Toxoplasma-positive pregnant women might in fact indicate an unrecognized serious public health problem.
\end{abstract}

One of the most common human parasites is the coccidium Toxoplasma gondii Nicolle et Manceau, 1908. Its prevalence in most countries varies from $20 \%$ to $80 \%$ - about $20 \%$ of pregnant women in Finland (Lappalainen et al. 1992), 27\% in Denmark (Lebech et al. 1993), 40\% in southern Italy (Buffolano et al. 1996), and $84 \%$ in Paris (Desmonts and Couvreur 1974). Four different forms of this parasitosis exist. The most serious is congenital toxoplasmosis, which often results in serious damage to the embryo and development of various malformations including microcephaly and hydrocephalus (Koppe and Rothova 1989). The second form is acute postnatally acquired toxoplasmosis. This form of the disease is characterized by occurrence of tachyzoites in the blood and other tissues. A broad spectrum of clinical symptoms from cervical lymphadenopathy, fever, and headache, to serious neurological and psychiatric complications (Kramer 1966) can accompany acute toxoplasmosis. Most symptoms of acute toxoplasmosis are relatively mild and harmless; therefore, this disease is usually misdiagnosed as a common bacterial or viral infection. In some cases acute toxoplasmosis develops into the third form, chronic toxoplasmosis, in which the symptoms of acute disease persist for many years. Usually, however, all symptoms spontaneously disappear within several weeks or months, and acute toxoplasmosis develops instead into a latent disease. During latent toxoplasmosis, Toxoplasma survives in its dormant form of bradyzoites in tissue cysts. In humans, this form of latent infection is probably never cleared and persists for the lifetime of the host.

Latent toxoplasmosis is generally considered to be asymptomatic (Markell et al. 1999, Roberts and Janovy 2000). In fact, most infected people (more than $80 \%$ of the population in some countries) never learn that they have contracted toxoplasmosis and are hosting dormant stages of the parasite for the rest of their lives. Serious health complications, sometimes even resulting in the death of the patient, usually occur only after severe damage to the immune system, e.g., artificial immunosuppression after transplantation, or AIDS (Heitman and Irizarry 1997, Mocsny 1992). Some authors also claim an association between long-term Toxoplasma infection and human abortions (Kimball et al. 1971). Transient reactivation of infection is sometimes suspected in cases of maternal-foetal parasite transmission and development of congenital toxoplasmosis (Fortier et al. 1991). Increased frequency of toxoplasmosis has also been found in patients with some forms of brain tumours (Ryan et al. 1993). The authors suggest that Toxoplasma cysts in brain tissue might result in a chronic local inflammation and trigger tumorigenic processes.

Recently, latent-toxoplasmosis-associated changes in human personality were observed and interpreted as the result of manipulation activity of the parasite (Flegr et al. 1996, 2000, 2003, Flegr and Havlíček 1999). This widely documented (Hutchison et al. 1980a, b, Arnott et al. 1990, Webster 1994, Webster et al. 1994, Berdoy et al. 1995, 2000, Hrdá et al. 2000) activity of Toxoplasma 
is seemingly aimed at inducing behavioural changes in the intermediate host (under natural conditions, a rodent) that can increase the probability of being killed and eaten by a definitive host (cat). Although the mechanism underlying this activity is not known for Toxoplasma, it could include the already described production or induction of a neuromodulator in the brain tissue of the infected host (Stibbs 1985).

In this study, we concentrated our attention on an alternative explanation for the observed personality changes, the by-product hypothesis. The prolonged presence of the parasite in host tissues can, theoretically, negatively influence the physical health of infected subjects. Infected subjects might, for example, suffer more frequent or more severe disease because of interference of the parasite with the immune system (Remington and Krahenbuhl 1982). Such worsening of the hosts' quality of life might then result in recognizable changes in the personality profiles of infected subjects. Therefore, we searched for possible changes in the health status of subjects with latent toxoplasmosis: namely, differences in body weight and other objective parameters in Toxoplasma-negative and Toxoplasmapositive women in the 16th week of gravidity.

\section{MATERIALS AND METHODS}

\section{Subjects}

The experimental set consisted of 824 women living mostly in central Prague who were serologically tested for toxoplasmosis in about the 16th week of their pregnancy. In the set, 621 women were diagnosed as Toxoplasma-negative while 203 women had titres of anti-Toxoplasma antibodies between $1: 8$ and 1:256. Anonymized clinical records contained antibody titres, age, body weight, and gravidity length estimated by a) ultrasonography and b) the date of last menses. The experimental set was filtered out to remove all subjects with antibody titres 1:64 and higher (whose weight might be transiently decreased because of relatively recent acute toxoplasmosis) and all outliers, i.e., the women with weight more than $2.5 \mathrm{SD}(\mathrm{SD}=9.07 \mathrm{~kg})$ away from the mean $(63.4 \mathrm{~kg})$ from the raw data. The filtrated set contained 758 women, however, the results obtained with whole set of 824 women were approximately same as those presented in this study. Results of correlation analysis indicated the existence of highly significant positive correlation between age and weight $(\mathrm{F}(1,755)=$ $11.8, \mathrm{p}=0.0006)$ and no correlation between the length of gravidity and weight $(\mathrm{F}(1,741)=0.123, \mathrm{p}=0.726)$. Therefore, we eliminated just the effect of age by computing standardized weights, i.e. standard residuals of the correlation between age and weight. The method of experimental subject recruitment as well as the personality data handling respected all rules of current Czech legislation.

\section{Immunological tests for toxoplasmosis}

In this study, we take latent toxoplasmosis to mean the presence of anti-Toxoplasma immunity in human subjects without any clinical symptoms of acute toxoplasmosis. Sera of pregnant women were tested at the National Reference Laboratory for Toxoplasmosis, National Institute of Public Health,
Prague, Czech Republic. Antibody concentrations were measured with IgG and IgM ELISA tests optimized for early detection of acute toxoplasmosis (Pokorný et al. 1989), and with a complement fixation test (CFT) that is more sensitive and therefore more suitable for detection of old Toxoplasma infections (Warren and Sabin 1942). The CFT titre of anti-Toxoplasma antibodies in sera was measured between 1:8 and 1:1024. All subjects with CFT titres from 1:8 to 1:256 were considered Toxoplasma-positive (and were screened for acute toxoplasmosis with IgG and IgM ELISA) and subjects with CFT titres lower than 1:8 were considered latent-Toxoplasmanegative. No subjects with CFT titres 1:8 or higher were negative by IgG ELISA ( $<250 \mathrm{IU}$ ). Subjects with CFT titres higher than 1:256 or with other serological or clinical indications of acute toxoplasmosis were not included in our study.

\section{Statistics}

Linear regression (to remove effects of age by computing standard residuals), $t$-tests with separate estimates of variance, and Levene's tests of homogeneity of variance were calculated with the Statistica ${ }^{\circledR}$ program. Permutation tests, including those with reassignment of false Toxoplasma-negatives into the positive group, were performed using the program TREEPT (PTPT) (Flegr and Záboj 1997) (a freeware program available at http://www.natur.cuni.cz/ flegr/programs/treept).

The algorithm of the permutation test with data reassignment was as follows: Particular percentage $(5 \%, 10 \%, 15 \%$, $20 \%$ or $25 \%$ ) of subjects with the highest (or lowest) values of the tested factor (either age-standardized weight or gravidity length) was relocated from the group of 584 Toxoplasma-negative women to the second group of 174 Toxoplasma-positive women. Then, the difference of means of these two groups was calculated. In the next 2,999 steps, the empirical values of the analysed variable were arbitrarily assigned into two groups of 584 and 174 cases, the particular percentage of highest (or lowest) cases from the larger group were relocated to the smaller group, and the difference of the means of the two groups was calculated. Finally, all 3,000 differences (including the one calculated from nonpermuted data) were sorted from highest to lowest. The percentage of difference higher or equal to that calculated on the basis of nonpermuted data was considered as the statistical significance (p), i.e., the probability of obtaining the same or higher difference of means of groups of 584 and 174 subjects assigned into these groups randomly. The test cannot resolve whether the two sets differ in variance or mean value.

\section{RESULTS}

A group of 758 women was tested for anti-Toxoplasma immunity in the 16th week of pregnancy (during compulsory testing for alpha-foetoprotein). Data recorded for each woman were: result of serological test for toxoplasmosis (antibody titre), age, body weight, and length of pregnancy (in weeks) estimated a) on the basis of ultrasonography and b) from the date of last menstruation. The results of $t$-tests suggested possible existence of difference in weight between Toxoplasmapositive and Toxoplasma-negative subjects. No significant difference was observed in age and length of pregnancy (Table 1). 
Table 1. Differences between Toxoplasma-positive and Toxoplasma-negative women compared by $t$-tests. The clinical records for 758 pregnant women contained the results of a complement fixation test for toxoplasmosis, age, body weight, and length of pregnancy (in weeks) estimated on the basis of ultrasonography and from the date of last menstruation. Body weight was agestandardized for each woman by computing a standard residual of linear regression between age and body weight. The SE represents standard errors and the $\mathrm{p}$ results of two-tailed $t$-test with separate variances.

\begin{tabular}{|l|c|c|c|c|c|c|c|}
\hline & $\begin{array}{c}\text { Mean (SE) } \\
\text { Toxo-negat. }\end{array}$ & $\begin{array}{c}\text { Mean (SE) } \\
\text { Toxo-posit. }\end{array}$ & $\begin{array}{c}\mathrm{n} \\
\text { Toxo-negat. }\end{array}$ & $\begin{array}{c}\mathrm{n} \\
\text { Toxo-posit. }\end{array}$ & $t$-statistics & $\mathrm{df}$ & $\mathrm{p}$ \\
\hline Age (years) & $27.0(0.19)$ & $27.8(0.39)$ & 583 & 174 & 1.77 & 755 & 0.08 \\
Weight (kg) & $62.7(0.34)$ & $64.2(0.70)$ & 584 & 174 & 2.21 & 756 & 0.03 \\
Standardized weight & $-0.03(0.04)$ & $0.09(0.08)$ & 583 & 174 & 2.02 & 755 & 0.04 \\
Menstruation & $15.7(0.04)$ & $15.8(0.11)$ & 579 & 173 & 0.64 & 750 & 0.53 \\
Ultrasonography & $16.0(0.05)$ & $16.0(0.11)$ & 574 & 169 & 0.44 & 741 & 0.66 \\
\hline
\end{tabular}

Table 2. Differences between Toxoplasma-positive and Toxoplasma-negative women tested by permutation tail probability test with data reassignment. The row headings show the fraction of reassigned cases, and the other cells of the table show the statistical significance (p) of two-sided permutation tests. The algorithm of the permutation test with data reassignment is described in the Materials and Methods section.

\begin{tabular}{|r|c|c|c|c|}
\hline & Weight & Standardized weight & Last menstruation & Ultrasonography \\
\hline $0 \%$ & 0.012 & 0.032 & 0.234 & 0.69 \\
$5 \%$ & 0.021 & 0.021 & 0.043 & 0.55 \\
$10 \%$ & 0.024 & 0.026 & 0.037 & 0.52 \\
$15 \%$ & 0.029 & 0.039 & 0.034 & 0.52 \\
$20 \%$ & 0.029 & 0.041 & 0.040 & 0.52 \\
$25 \%$ & 0.028 & 0.043 & 0.053 & 0.52 \\
\hline
\end{tabular}

However, the results of Levene's tests of homogeneity of variances also suggested the existence of difference in variances in analysed variables between Toxoplasma-positive and Toxoplasma-free subsets. Therefore, the difference between Toxoplasma-negative and Toxoplasma-positive women was also tested with a permutation test that is insensitive to many irregularities in data distribution. Results showed that differences probably exist in the weight of Toxoplasma-negative and Toxoplasma-positive women (see the first row of Table 2). The effect of latent toxoplasmosis can be expected to increase with the length of Toxoplasma infection (Flegr et al. 1996, 2000). The moment of Toxoplasma infection is usually not known for most subjects with latent toxoplasmosis. However, it can be indirectly estimated based on the level of specific antibodies, which is usually very high during acute toxoplasmosis but decreases within months or several years after the infection (Konishi 1989). Due to large variability in the rate of this decrease and due to fluctuations of the antibody level in time, the antibody titre cannot be used for the estimation of duration of toxoplasmosis in an individual patient. Statistically, however, the negative correlation between the level of antibody and duration of the infection exists and therefore can be used for this purpose in population-based studies. Therefore, the influence of latent toxoplasmosis on the weight of infected people can be estimated from the graph of correlation between antibody titre and weight of the subjects.
Fig. 1 shows a positive correlation between body weight and antibody titre, which can be interpreted as a negative correlation between body weight and duration of latent toxoplasmosis (Kendal Tau $=0.103, Z=2.02, p$ $=0.043$, two-tailed test).

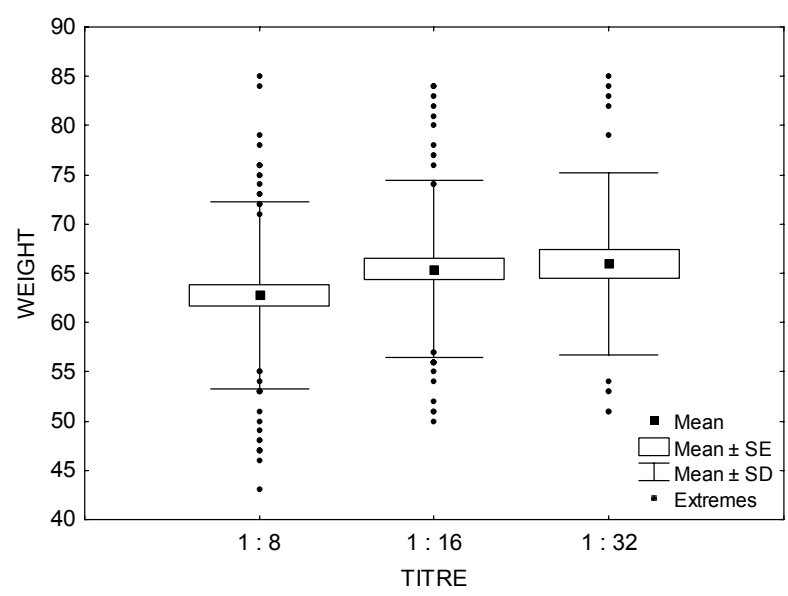

Fig. 1. Correlation between antibody titre and weight of subjects. The abscissa shows the body weight (in $\mathrm{kg}$ ) and the ordinate shows the titre of specific antibodies measured by complement fixation test. The experimental set was filtered out to remove all subjects with antibody titres 1:64 and higher (whose weight might be transiently decreased because of relatively recent acute toxoplasmosis). The subjects differing more then $7 \mathrm{SE}$ (standard errors) from the mean of particular titre-set were marked as extremes. The number of subjects in with titres $1: 8,1: 16,1: 32,1: 64$ and $1: 128$ was $73,63,38,12$ and 3 , respectively. 
It is well known (Fruhbauer et al. 1990, Cubitt et al. 1992, Petithory et al. 1996) that serological tests are optimized and primarily intended for diagnosis of acute toxoplasmosis, and therefore may provide false negative results in subjects with old Toxoplasma infections (having low titres of antibodies). Therefore, our subset of Toxoplasma-negative women was certainly contaminated by an unknown number of false negatives, that may actually have been on average the most severely latent-toxoplasmosis-influenced subjects in the set (for example, those subjects with greatest decrease of body weight). For technical reasons (the data were collected more then 6 years ago) it was not possible to retest the suspect women with second more sensitive test. However, the contamination with false negatives can be expost revealed (and eliminated) by permutation tests with reassignment of suspect cases between the sets (Flegr and Havlíček 1999), the results of which are shown in Table 2. Evidently, in any permutation test with reassignment of $5-25 \%$ of the lightest subjects from the Toxoplasma-negative to Toxoplasma-positive set, the differences between Toxoplasma-negative and Toxoplasma-positive women become apparent. Table 2 lists only the results of two-tailed tests; in fact, one-tailed tests, which test the hypothesis about decreased weight in Toxoplasma-positive women and provide two times higher significance, are more appropriate.

Similarly, after reassignment from the Toxoplasmanegative to Toxoplasma-positive set of 5-25\% of the women with longest gravidity as estimated by date of last menstruation, a highly significant difference in average gravidity length (with the greater length in Toxoplasma-positive women) became evident.

\section{DISCUSSION}

The existence of a negative correlation between duration of infection and body weight in Toxoplasma-positive subjects, as well as a lower average body weight in the subset of Toxoplasma-positive women than in the subset of Toxoplasma-negative ones revealed by the permutation tests, suggest a negative influence of latent toxoplasmosis on human health.

Negative correlation between the length of latent toxoplasmosis and body weight seems not to correspond with the fact that the average weight in the Toxoplasmanegative subset is lower than in the Toxoplasma-positive subset. However, the results of permutation tests with data reassignment clearly show that this paradox is only the result of an experimental artefact: namely, that the serological tests provide false negative results in subjects with lower antibody titres (Fruhbauer et al. 1990, Petithory et al. 1996). The probability of obtaining such false negative results negatively correlates with antibody titre (which decreases with the length of latent infection), and is therefore higher in subjects with the longest duration of latent toxoplasmosis. Our results showed that the women with the longest duration of toxoplasmosis had the lowest body weight. Therefore, their misincorporation into the Toxoplasma-negative subset might not only flatten out the difference between the subsets, but in some situations might even invert the expected relations between the subsets (causing a lower, instead of higher, average weight of subjects in the Toxoplasma-negative subset).

The hypothesis about the role of false-negatives in the Toxoplasma-negative subset was confirmed by the permutation tests with data reassignment. When the test was performed with reassignment of $5-25 \%$ of the lightest women from a large subset of 584 subjects into the smaller subset of 174 subjects, the difference between average weight in these two subsets computed from the real (nonpermuted) data fell into the upper 3\% quantile. This suggests that there is only about $3 \%$ probability that Toxoplasma-positive women have the same average weight as the Toxoplasma-negative ones.

We can only speculate on the mechanism of the observed latent toxoplasmosis effect. The decrease of weight of infected women can be either a direct effect of the deterioration of health of infected subjects or an indirect effect of, for example, higher activity (and therefore caloric output) amongst infected than uninfected women. The later explanation would be compatible with results of earlier animal studies that indicated a higher activity of infected rodents (Hutchison et al. 1980b, Hay et al. 1983, Webster 1994).

Theoretically, the existence of correlation between latent toxoplasmosis and weight of pregnant women can be also caused by correlation of both probability of Toxoplasma infection and body weight with some third common factor, such as social-economic status of women (e.g. a higher body-shape awareness in higher income groups). We have no data that could be used to test this hypothesis. It could be only argued that if this hypothesis was correct, we could hardly expect the existence of the observed correlation between decrease of body weight and duration of latent toxoplasmosis. Also the social stratification of the post-communist Czech Republic is rather undeveloped.

An unexpected result of our study was the observed longer duration of gravidity estimated from the date of last menstruation in the set of Toxoplasma-positive women. As such a difference did not exist in the length of gravidity estimated by ultrasonography, two different explanations of this phenomenon can be suggested. It could be caused, for example, by a shift of the moment of fertilisation into the late phases of the menstrual cycle. The second possible explanation is based on a possible retardation of foetal growth in Toxoplasmapositive women. If such retardation exists, then it would result in incorrect (too low) ultrasonography-based estimates of gravidity length. The date of the alpha-foetoprotein test is always scheduled on the basis of the results of ultrasonography; therefore, at the time of the serological test, both the Toxoplasma-negative and 
Toxoplasma-positive women in our experimental set had exactly the same length of gravidity as estimated by ultrasonography (16.0 weeks).

However, if growth of the foetus is slower in Toxoplasma-positive women, their length of gravidity is systematically underestimated by ultrasonography. Due to this systematic error, the gravidity of Toxoplasmapositive women would very often be longer than the 16 weeks suggested by ultrasonography at the time of serological tests. This possibility is reflected by the significantly longer gravidity values estimated from date of last menses. It cannot be decided on the basis of our data which explanation of the phenomenon is correct. To answer this, it would be very important to obtain separate embryonic growth curves for Toxoplasmanegative and Toxoplasma-positive mothers and average birth-weights for their children.

Latent toxoplasmosis is usually considered to be an asymptomatic parasitosis having practically no impact on the health of immunocompetent subjects. However, despite an extremely high prevalence of this form of toxoplasmosis in many countries, only minimal attention is paid to the study of its potential impact on human health (Holliman 1997). Certain studies demonstrate possible correlation of latent toxoplasmosis with some types of brain tumours (Ryan et al. 1993) or with specific changes in personality profiles of infected subjects (Flegr et al. 1996, 2000, 2003, Flegr and Havlíček 1999). Our results, namely, decreased body weight of Toxoplasma-positive pregnant women (and possibly also decreased growth rate of the foetus), suggest that latent toxoplasmosis might in some way negatively affect the health of infected subjects. Because of its extremely high prevalence in the world population, latent toxoplasmosis, the mildest form of Toxoplasma infection, might in fact represent a serious and highly underestimated public health problem.

Acknowledgement. This research was supported by the Ministry of Education, Youth and Sport of the Czech Republic (grant no. 0021620828).

\section{REFERENCES}

ARNOTT M.A., CASSELLA J.P., AITKEN P.P., HAY J. 1990: Social interactions of mice with congenital Toxoplasma infection. Ann. Trop. Med. Parasitol. 84: 149-156.

BERDOY M., WEBSTER J.P., MacDONALD D.W. 1995: Parasite-altered behaviour: is the effect of Toxoplasma gondii on Rattus norvegicus specific? Parasitology 111: 403-409.

BERDOY M., WEBSTER J.P., MacDONALD D.W. 2000: Fatal attraction in rats infected with Toxoplasma gondii. Proc. R. Soc. London, B Biol. Sci., 267: 1591-1594.

BUFFOLANO W., GILBERT R.E., HOLLAND F.J., FRATTA D., PALUMBO F., ADES A.E. 1996: Risk factors for recent Toxoplasma infection in pregnant women in Naples. Epidemiol. Infect. 116: 347-351.

CUBITT W.D., ADES A.E., PECKHAM C.S. 1992: Evaluation of five commercial assays for screening antenatal sera for antibodies to Toxoplasma gondii. J. Clin. Pathol. 45: 435-438.

DESMONTS G., COUVREUR J. 1974: Congenital toxoplasmosis. A prospective study of 378 pregnancies. N. Engl. J. Med. 290: 1110-1116.

FLEGR J., HAVLÍČEK J. 1999: Changes in the personality profile of young women with latent toxoplasmosis. Folia Parasitol. 46: 22-28.

FLEGR J., KODYM P., TOLAROVÁ V. 2000: Correlation of duration of latent Toxoplasma gondii infection with personality changes in women. Biol. Psychol. 53: 57-68.

FLEGR J., PREISS M., KLOSE J., HAVLÍČEK J., VITÁKOVÁ M., KODYM P. 2003: Decreased level of psychobiological factor novelty seeking and lower intelligence in men latently infected with the protozoan parasite Toxoplasma gondii. Dopamine, a missing link between schizophrenia and toxoplasmosis? Biol. Psychol. 63: 253-268.

FLEGR J., ZÁBOJ P. 1997: PTPT, the freeware program for permutation testing concordance between phylogeny and the distribution of phenetic traits. Acta Soc. Zool. Bohem. 61: 91-95.

FLEGR J., ZITKOVÁ S., KODYM P., FRYNTA D. 1996: Induction of changes in human behaviour by the parasitic protozoan Toxoplasma gondii. Parasitology 113: 49-54.

FORTIER B., AISSI E., AJANA F., DIEUSART P., DENIS P., MARTIN D.L., LECOMTE-HOUCKE M., VINATIER D. 1991: Spontaneous abortion and reinfection by Toxoplasma gondii [letter]. Lancet 338: 444.

FRUHBAUER Z., POKORNÝ J., ZITOVÁ D., SÝKORA J., ZÁSTĚRA M. 1990: Interpretation of antitoxoplasma antibody findings. Česk. Epidemiol. Mikrobiol. Imunol. 39: 327-334. (In Czech.)

HAY J., HUTCHISON W.M., AITKEN P.P., GRAHAM D.I. 1983: The effect of congenital and adult-acquired Toxoplasma infections on activity and responsiveness to novel stimulation in mice. Ann. Trop. Med. Parasitol. 77: 483495.

HEITMAN B.B., IRIZARRY A.F. 1997: Recognition and management of toxoplasmosis. Nurse. Pract. 22: 75, 7986.

HOLLIMAN R.E. 1997: Toxoplasmosis, behaviour and personality. J. Infect. 35: 105-110.

HRDÁ S., VOTÝPKA J., KODYM P., FLEGR J. 2000: Transient nature of Toxoplasma gondii-induced behavioral changes in mice. J. Parasitol. 86: 657-663.

HUTCHISON W.M., AITKEN P.P., WELLS B.W.P. 1980a: Chronic Toxoplasma infection and familiarity-novelty discrimination in the mouse. Ann. Trop. Med. Parasitol. 74: $145-150$.

HUTCHISON W.M., BRADLEY M., CHEYNE W.M., WELLS B.W.P., HAY J. 1980b: Behavioural abnormalities in Toxoplasma-infected mice. Ann. Trop. Med. Parasitol. 74: 337-345. 
KIMBALL A.C., KEAN B.H., FUCHS F. 1971: The role of toxoplasmosis in abortion. Am. J. Obstet. Gynecol. 111: 219-226.

KONISHI E. 1989: Annual change in immunoglobulin G and M antibody levels to Toxoplasma gondii in human sera. Microbiol. Immunol. 33: 403-411.

KOPPE J.G., ROTHOVA A. 1989: Congenital toxoplasmosis. A long-term follow-up of 20 years. Int. Ophthalmol. 13: 387-390.

KRAMER W. 1966: Frontiers of neurological diagnosis in acquired toxoplasmosis. Psychiatr. Neurol. Neurochir. 69: 43-64.

LAPPALAINEN M., KOSKELA P., HEDMAN K., TERAMO K., AMMALA P., HIILESMAA V., KOSKINIEMI M. 1992: Incidence of primary Toxoplasma infections during pregnancy in Southern Finland - A prospective cohort study. Scand. J. Infect. Dis. 24: 97-104.

LEBECH M., LARSEN S.O., PETERSEN E. 1993: Prevalence, incidence and geographical distribution of Toxoplasma gondii antibodies in pregnant women in Denmark. Scand. J. Infect. Dis. 25: 751-756.

MARKELL E.K., JOHN D.T., KROTOSKI W.A. 1999: Markell and Voge's Medical Parasitology. 8 ed. W.B. Saunders Company, Philadelphia, 501 pp.

MOCSNY N. 1992: Toxoplasmic encephalitis in the AIDS patient. J. Neurosci. Nurs. 24: 30-33.

PETITHORY J.C., REITER-OWONA I., BERTHELOT F., MILGRAM M., DE L.J., PETERSEN E. 1996: Performance of European laboratories testing serum samples for Toxoplasma gondii. Eur. J. Clin. Microbiol. Infect. Dis. 15: 45-49.
POKORNÝ J., FRUHBAUER Z., POLEDŇÁKOVÁ S., SÝKORA J., ZÁSTĚRA M., FIALOVÁ D. 1989: Assessment of antitoxoplasmatic IgG antibodies with the ELISA method. Česk. Epidemiol. 38: 355-361. (In Czech.)

REMINGTON J.S., KRAHENBUHL J.L. 1982: Immunology of Toxoplasma gondii. In: A.J. Nahmias and J. O'Reilly (Eds.), Immunology of Human Infection, Part II. Plenum Publishing Corporation, New York, pp. 327-371.

ROBERTS L.S., JANOVY J. Jr. 2000: Gerald S. Schmidt \& Larry S. Roberts' Foundations of Parasitology. 6th Edition. McGraw-Hill Companies, Boston, 670 pp.

RYAN P., HURLEY S.F., JOHNSON A.M., SALZBERG M., LEE M.W., NORTH J.B., McNEIL J.J., McMICHAEL A.J. 1993: Tumours of the brain and presence of antibodies to Toxoplasma gondii. Int. J. Epidemiol. 22: 412419.

STIBBS H.H. 1985: Changes in brain concentrations of catecholamines and indoleamines in Toxoplasma gondii infected mice. Ann. Trop. Med. Parasitol. 79: 153-157.

WARREN J., SABIN A.B. 1942: The complement fixation reaction in toxoplasmic infection. Proc. Soc. Exp. Biol. Med. 51: 11-16.

WEBSTER J.P. 1994: The effect of Toxoplasma gondii and other parasites on activity levels in wild and hybrid Rattus norvegicus. Parasitology 109: 583-589.

WEBSTER J.P., BRUNTON C.F.A., MacDONALD D.W. 1994: Effect of Toxoplasma gondii upon neophobic behaviour in wild brown rats, Rattus norvegicus. Parasitology 109: 37-43.

Accepted 10 September 2004 